\title{
Problem Solving Therapy-induced Amygdala Engagement Mediates Weight Loss and Lifestyle Behavior Change in Patients With Obesity and Depression: A Randomized Controlled Trial
}

Nan Lv

University of Illinois at Chicago Institute for Health Research and Policy

Wesley K Lefferts

University of Illinois at Chicago Institute for Health Research and Policy

Lan Xiao

Stanford University

Andrea N Goldstein-Piekarski

Stanford University

Joseph Wielgosz

Stanford University

Philip W Lavori

Stanford University

Janine M Simmons

National Institute on Aging

Joshua M Smyth

Pennsylvania State University University Park : Penn State

Patrick Stetz

Stanford University

Elizabeth M Venditti

University of Pittsburgh

Megan A Lewis

RTI International

Lisa G Rosas

Stanford University

Mark B Snowden

University of Washington

Olusola A Ajilore

University of Illinois at Chicago

Trisha Suppes

Stanford University 


\section{Leanne M Williams}

Stanford University

Jun Ma ( $\triangle$ maj2015@uic.edu )

University of Illinois at Chicago College of Medicine

\section{Research}

Keywords: amygdala, negative affect, human brain imaging, weight loss, diet, physical activity

Posted Date: August 5th, 2020

DOI: https://doi.org/10.21203/rs.3.rs-53210/v1

License: (c) (1) This work is licensed under a Creative Commons Attribution 4.0 International License. Read Full License 


\section{Abstract}

Background: Behavioral interventions for obesity have modest and variable effectiveness. Emotion dysregulation may hinder effective weight loss interventions, especially among those with comorbid depression. Whether neural mechanisms related to emotion dysregulation mediate the effect of behavioral intervention on improving health behaviors in obesity combined with depression is unknown. Hyperactivation of the amygdala and loss of functional connectivity with the anterior cingulate regions are neural characteristics of unhealthy responses to negative emotion and accompanying emotion dysregulation.

Methods: Using data from a randomized clinical trial of 108 primary care adult patients with obesity and depression, we investigated whether changes in amygdala activity and connectivity following problem solving therapy for depression over 2 months mediate weight loss, physical activity, and/or dietary outcomes at 6 and 12 months.

Results: Compared with controls $(n=49)$, intervention participants $(n=59)$ had a significant blunting of the otherwise unhealthy increase in activity of the bilateral amygdala at 2 months (right: $-0.83,95 \% \mathrm{Cl}-1.55$ to -0.11 ; left: $-0.86,-1.63$ to -0.10 ). While increases in amygdala activity significantly correlated with decreases in leisure-time physical activity levels and total energy expenditure at 12 months in the control group, this relationship was tempered or reversed among intervention participants (for physical activity, right: usual care $-692.9,-1365.3$ to -20.6 ; interaction $652.2,-115.4$ to 1419.9 ; left: usual care -686.0 , -1127.9 to -244.1 ; interaction $664.7,73.1$ to 1256.4 ; for energy expenditure, right: usual care $-1.82,-3.08$ to -0.56 ; interaction $1.94,0.50$ to 3.38 ; left: usual care $-1.72,-2.51$ to -0.93 ; interaction $1.89,0.84$ to 2.94 ). Compared with controls, intervention participants had a significant increase of the otherwise unhealthy loss of amygdala-subgenual anterior cingulate connectivity at 2 months $(0.78,0.05$ to 1.52$)$. This increase in functional connectivity significantly correlated with a decrease in BMI at 6 months among intervention participants (usual care $0.04,-0.42$ to 0.50 ; interaction $-0.61,-1.20$ to -0.02 ) and an increase in fruit and vegetable intake at 12 months across all participants (usual care 1.42, 0.27 to 2.57 ; interaction $-0.95,-2.36$ to 0.46$)$.

Conclusions: These findings highlight potential neural mechanism for optimizing the efficacy of behavioral intervention in comorbid obesity and depression.

Trial registration: ClinicalTrials.gov\#NCT02246413.

URL: https://clinicaltrials.gov/ct2/show/NCT02246413.

\section{Background}

Obesity affects $40 \%$ of the United States (US) adult population (1) and often manifests with comorbid mood disorders such as depression (2). Weight loss is critical in adults with co-existing obesity and depression to prevent development of additional chronic disease (e.g., type 2 diabetes and cardiovascular 
disease) (3). Unfortunately, adults with obesity and comorbid depression face additional psychological, physiological, and behavioral challenges to weight loss that impair adherence and response to current treatment.

Current behavioral interventions designed to treat obesity and depression have modest overall effectiveness, with substantial heterogeneity in treatment outcomes across patients. Recent evidence suggests that emotion dysregulation may be an important barrier to effective weight loss treatment and maintenance. Studies have shown that emotion dysregulation is associated with obesity (4), depression (5), and maladaptive behaviors (e.g., overeating and binge eating) (6-10). Emotion dysregulation may limit the effectiveness of weight loss interventions by increasing vulnerability to maladaptive behaviors that accompany stress and negative affect. Indeed, stress and negative affect can elicit avoidance or minimization coping strategies such as overeating and binge eating $(8,11)$. Moreover, stress is associated with less engagement in physical activity among individuals already exhibiting low levels of physical activity (12). As such, emotion dysregulation may limit the effectiveness of weight loss interventions by (i) rendering individuals vulnerable to stress/negative affect-induced increases in caloric intake and (ii) impairing motivation and efforts to be physically active. One approach to address this limitation is to address depression within the context of weight loss interventions. Recently, the Research Aimed at Improving Both Mood and Weight (RAINBOW) trial tested a yearlong integrated collaborative care intervention that combined problem solving therapy (PST) for depression care management and self-directed Group Lifestyle Balance (GLB) program for weight loss, among primary care adult patients with comorbid obesity and depression. Compared with usual care, this intervention led to significantly improved weight loss and depressive symptoms through 12 months (13). However, the effectiveness was modest, with substantial heterogeneity in treatment outcomes across patients (14). In alignment with the Science of Behavior Change (SOBC) experimental medicine approach, one strategy to this challenge is to better understand the degree to which engagement of specific neural targets relevant to emotion regulation promotes weight loss, or more specifically, improved diet and physical activity among adults with comorbid obesity and depression. Moreover, such an approach may offer mechanistic insights and suggest new approaches to optimize the effectiveness of weight loss interventions in this high-risk comorbid population.

Functional neuroimaging studies highlight the central role of the amygdala in neural circuits engaged by bottom-up and top-down appraisal and response to salient emotion stimuli such as threat (15), and these findings highlight homologies with animal models of threat responses. Medial prefrontal regions to which the amygdala connects, such as the anterior cingulate cortex (ACC), play a role in regulating the amygdala and emotional responses $(15,16)$. Previous reviews have synthesized the literature on neural circuit dysfunctions characteristic of emotion dysregulation and of mood disorders such as depression $(17,18)$. For example, depression has been characterized by heightened amygdala activity to threatrelated and mood-congruent sad emotion stimuli along with a loss of amygdala regulation by cortical regions such as the anterior cingulate (16). Reduced functional connectivity between the amygdala and subgenual ACC (sgACC) has also been observed in response to threat and sad stimuli in unmedicated participants with major depressive disorder (19). Changes in amygdala activity and amygdala-sgACC 
functional connectivity correlate with responses to interventions for depression, such as cognitivebehavioral therapy $(20,21)$ and antidepressants $(22)$. However, these amygdala and sgACC targets have not been investigated systematically in a randomized controlled design using an established behavioral intervention for comorbid obesity and depression. It remains unknown as to whether changes in these neural targets mediate subsequent improvements in diet, physical activity, and weight among adults with comorbid obesity and depression.

The current analysis leveraged neuroimaging data from the ENGAGE study, which was conducted in a RAINBOW subsample to investigate potential neural mechanisms underlying the integrated intervention for obesity and depression (23). To specifically investigate whether neural targets related to emotion regulation following treatment of depression mediates weight management, this analysis used functional magnetic resonance imaging (fMRI) data at baseline and 2 months, as well as diet, physical activity, and weight outcome data at baseline, 6 , and 12 months. The interval between baseline and 2 months coincided with initial PST for depression before the weight loss treatment component of the integrated intervention began. The a priori neural targets included the affective circuits involved in the regulation of negative emotions (threat and sadness) and constituent regions in these circuits. We hypothesized that changes in these neural targets at 2 months would mediate subsequent changes in diet, physical activity, and weight at 6 and/or 12 months.

\section{Methods}

The Institutional Review Boards for the University of Illinois at Chicago and the Stanford University approved the study. All participants provided written informed consent. Protocols of the RAINBOW and ENGAGE trials were previously published $(23,24)$.

\section{Participants}

The ENGAGE sample $(n=108)$ was a subset of the RAINBOW sample $(n=409)$ who also consented to the ENGAGE trial (Figure 1). Participants were recruited from family and internal medicine departments in 4 medical centers of Sutter Health's Palo Alto Medical Foundation. Adults of any sex and race/ethnicity were eligible if they had body mass index (BMI) $\geq 30$ ( $\geq 27$ if Asian) and depressive symptoms defined by a 9-item Patient Health Questionnaire (PHQ-9) score $\geq 10$, without serious medical or psychiatric comorbidities or other exclusions.

\section{Study_procedures}

Potentially eligible patients identified from the electronic health records (EHR) received recruitment invitations to complete initial eligibility screening. Patients passing the screening attended baseline visits to complete a physical exam and questionnaires and separate fMRI visits. A study physician performed final EHR reviews to rule out any comorbidities that might have excluded the participant. If fully eligible, patients were randomized to receive the study intervention or usual care and were followed up at 2 (end of the PST-only component of the intervention), 6 (end of the intensive treatment phase of the 
intervention), and 12 months (end of the maintenance phase of the intervention). Funding of the ENGAGE study began after about half of the RAINBOW sample had been enrolled, and subsequent participants were offered the options to enroll in RAINBOW only or in RAINBOW and ENGAGE during the informed consent.

\section{Randomization and blinding}

RAINBOW participants (including those who also enrolled in ENGAGE) were randomly assigned to receive the Integrated Coaching for Better Mood and Weight (I-CARE) intervention or usual care using an online system (25) based on Pocock's covariate-adaptive minimization (26). This method was used to achieve better-than-chance marginal balance across multiple baseline characteristics: clinic, age, sex, race/ethnicity, education, BMI, depression Symptom Checklist 20-items (SCL-20) score, antidepressant medications, and number of hospitalizations in the past year. After the ENGAGE study began, participants' choice of enrolling in RAINBOW only or in RAINBOW and ENGAGE was added as a balancing factor. Investigators not involved in delivery of the study intervention, the data and safety monitoring board, outcome assessors, and the data analyst were blinded to participants' treatment assignment until the end of the study.

\section{Intervention}

The I-CARE intervention combines the GLB (27) program for weight loss and the PEARLS program for depression care management $(28,29)$. The GLB program is self-directed using home-viewed GLB videos and promotes modest (5-10\%) weight loss through calorie-reduced, healthy dietary changes and gradually increased physical activity. The PEARLS program uses PST with behavioral activation strategies as first-line, plus stepwise increases in doses and number of antidepressant medications as needed. The 12-month intervention included 6 in-person individual PST sessions for depression by 2 months, 3 additional PST sessions for depression and 11 home videos on lifestyle changes for weight loss by 6 months, and 6 maintenance calls by 12 months. Participants received self-care materials, including intervention handouts, a DVD set or online access code for the GLB videos, a wireless activity tracker with replacement batteries, and written instructions for creating a MyFitnessPal.com account to track weight and dietary intake. A trained health coach delivered the in-person PST sessions and met every 1-2 weeks with an intervention manager, a psychiatrist, and a primary care physician to discuss participants with poor progress. Based on these discussions, the psychiatrist might recommend initiating or adjusting antidepressant medications for a patient and would communicate with the patient's primary care physician who was responsible for medication management.

\section{Usual care}

Participants in the intervention and usual care groups continued to receive medical care from their primary care physicians. All participants also received information on mental health services and weight management and other wellness programs routinely available at their clinic. Control participants received a wireless activity tracker with batteries but not any other intervention materials. 


\section{Outcome measures}

Assessments of BMI, dietary intake, and physical activity occurred at baseline, 6, and 12 months. Following standardized protocols (30), trained research staff measured height (baseline only) and body weight. BMI was calculated as weight $(\mathrm{kg})$ divided by height squared $\left(\mathrm{m}^{2}\right)$.

Trained staff interviewed participants to conduct multiple-pass 24-hour recalls using the Nutrition Data System for Research (NDSR) (31) and 7-day Physical Activity Recalls per standardized protocol $(32,33)$. As an index of overall diet quality, the DASH (Dietary Approach to Stop Hypertension) score was computed based on 9 nutrient targets (total fat, saturated fat, protein, cholesterol, fiber, magnesium, calcium, sodium and potassium) (34) provided by the NDSR software. For each nutrient target, participants were assigned a point if they achieved the target and half a point if they achieved an intermediate target (i.e., half-way between the DASH target and the population mean), and the DASH score was the sum of points across all 9 nutrients $(35,36)$. Additional daily dietary target measures included fruits and vegetables (servings), total caloric intake (kilocalories), and total fat consumption (grams).

Physical activity was assessed as Metabolic Equivalent Task (MET) minutes per week of leisure time physical activity based on the sum of the weighted physical activity minutes for moderate (weight: 4 METs), hard (weight: 6 METs), and very hard (weight: 10 METs) activities from the 7-day Physical Activity Recall $(37,38)$. Also, total energy expenditure in kilocalories per kilogram per day was derived from METminutes/day using the conversion $1 \mathrm{MET}=1 \mathrm{kcal} / \mathrm{kg} / \mathrm{hour}(37,38)$.

\section{Potential mediators: neural circuit targets}

fMRI data were collected at baseline and 2 months. Neural circuit targets were defined and quantified by the following procedures:

\section{1. i) Sequences}

We implemented previously established functional neuroimaging sequences and parameters as defined in our pre-specified protocol ((23); see Additional File 1 for details).

\section{1. ii) Paradigms}

Neural circuits of interest, anchored in the amygdala and ACC, were engaged using established experimental paradigms in which participants were instructed to view standardized facial expressions of emotion depicting both threat and sadness $(22,39,40)$. Informed by findings for depression we focused on the non-conscious viewing condition for threat and the conscious viewing condition for sad. See Additional File 1 for description of the task and imaging parameters).

iii) Neural circuit target regions of interest

Regions of interest for the neural circuit engaged by threat were the amygdala (bilaterally) and the sgACC and for the neural circuit engaged by sad, the amygdala (bilaterally), dorsal anterior cingulate, and 
anterior insula (bilaterally). These regions of interest were defined previously using a systematic procedure $(41)$ informed by our theoretical taxonomy $(17,18)$. See Additional File 1 for additional details of region definitions.

\section{1. iv) Computing circuit function for a healthy reference standard sample}

Regional activation and region-to-region connectivity values for these regions of interest were quantified for a healthy reference sample available to this study as a healthy reference standard for computing extent of neural circuit dysfunction in the clinical participants. We previously established that the healthy sample was characterized by good quality data (62). Healthy reference values for activation of regions of interest for the contrast of each emotion minus neutral and psychophysiological interaction (PPI) analysis for region-to-region functional connectivity were computed. These values were mean-centered, and scaled to be expressed as standard deviation units. A global circuit dysfunction score was computed by averaging the constituent activation and connectivity values for circuits engaged by threat and sad.

The reference sample included 40 healthy individuals without depression or obesity (mean age 33.9 years, SD 13.4, 50\% female, 52\% non-Hispanic White, mean BMI 24.1, SD 3.5, and mean PHQ-9 1.1, SD 2.2) completed identical fMRI assays.

1. v) Computing_circuit dysfunction for the present clinical trial sample

Patient-level activation for the regions of interest were derived in a manner consistent with the methods used for the healthy reference sample and that have been published previously $(22,39-41)$ and described in detail in Additional File 1. Similarly, PPI analyses, using an established approach (42) were used to quantify functional connectivity between regions of interest. See Additional File 1 for details.

\section{1. vi) Standardizing_circuit dysfunction}

Having identified the circuit dysfunction values for our clinical sample, we expressed each of these activation and connectivity values in standard deviation units relative to our healthy reference sample in order to interpret circuit dysfunction in clinical participants relative to a healthy reference group.(41) Through this procedure, global circuit dysfunction scores were interpretable relative to a healthy reference mean of zero. Then the values were winsorized using $+/-3$ standard deviations.

As part of the standardization process we ensured that the directionality of each dysfunction value (i.e., activity of a region or region-to-region connectivity) was oriented so that greater scores always indicated greater dysfunction, according to our theoretical framework $(17,18)$. This process resulted in a single score for activation and connectivity value for each region of interest or pairs of regions. We also averaged these values in order to generate a global circuit dysfunction score for the neural circuit engaged by threat and sad.

\section{Statistical analysis}


Longitudinal mediation was analyzed to assess whether the change in a potential mediator from baseline to 2 months mediated the change in an outcome from baseline to 6 or 12 months. Based on the approach described by Kraemer et al. (43), mediation exists if there is a significant effect of the intervention $(\mathrm{X})$ on the potential mediator $(\mathrm{M}, \mathrm{XàM}$ Path $\mathrm{A})$ and the potential mediator is significantly associated with the outcome either as a simple effect in the usual care group (or usual care effect) or an interaction effect with the intervention compared to the usual care group (MàY Path B) (Figure 2). Path A was assessed using the $t$ test to obtain between-group differences of a potential mediator and $95 \%$ confidence intervals (Cls). Path B was tested using the ordinary least square regression to assess the association of a potential mediator with an outcome in the usual care group (the usual care effect) and by interaction with the intervention relative to the usual care group (the interaction effect), adjusting for the outcome at baseline. The usual care effect reflects the effect in the usual care group and the interaction effect reflects the effect in the intervention group relative to the usual care group. Participants were analyzed based on the group to which they were randomly assigned using all available data.

All analyses were conducted using SAS, version 9.4 (SAS Institute Inc., Cary, North Carolina); statistical significance defined by 2 -sided $P<0.05$. $P$ values were not adjusted for multiple comparisons as this was an exploratory study, and additional dedicated studies are needed to confirm the results.(44) Figures were generated using the ggplot2 package in $\mathrm{R}$.

\section{Results}

\section{Sample characteristics}

Baseline characteristics of the ENGAGE sample ( $n=108)$, a subset of the RAINBOW sample $(n=409)(13)$, are shown in Table 1. At baseline, similar to the RAINBOW sample, ENGAGE participants had moderately severe obesity, mean BMI (35.5, SD 5.1), and moderate depression, mean SCL-20 score (1.5, SD 0.5).

\section{Neural circuit targets engaged by threat-related stimuli}

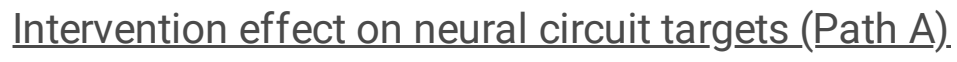

Compared with usual care participants, intervention participants showed a significant blunting of the otherwise unhealthy hyperactivation of the bilateral amygdala engaged by threat stimuli at 2 months (right: $-0.83,95 \% \mathrm{Cl}-1.55$ to $-0.11, \mathrm{P}=0.02$; left: $-0.86,95 \% \mathrm{Cl}-1.63$ to $-0.10, \mathrm{P}=0.03$ ) (Table 2 and Figure 3). Compared with usual care participants, intervention participants also showed a significant increase of functional connectivity between the left amygdala and bilateral sgACC for these stimuli at 2 months $(0.78,95 \% \mathrm{Cl} 0.05$ to $1.52, \mathrm{P}=0.04)$. When the amygdala activity and amygdala-sgACC connectivity were combined within a single global circuit dysfunction score, intervention participants similarly showed a lessening of dysfunction at 2 months $(-0.53,95 \% \mathrm{Cl}-0.93$ to $-0.13 ; \mathrm{P}=0.01)$, compared with usual care participants.

Association of neural circuit targets with outcomes (Path B). 
Increases in the circuit dysfunction score and activity in the bilateral amygdala for threat stimuli at 2 months significantly correlated with decreases in leisure-time physical activity level and total energy expenditure at 12 months among usual care participants, but this relationship was tempered or reversed among intervention participants (Figure 3). In relation to leisure-time physical activity in MET minutes per week, for circuit dysfunction score, the usual care effect was $\beta=-1943.0$ (95\% Cl -2861.5 to -1024.5 , $P<0.001)$ and the interaction effect was $\beta=1847.5$ (95\% Cl 721.5 to $2973.6, P=0.002)$; for right amygdala threat reactivity, the usual care effect was $\beta=-692.9(95 \% \mathrm{Cl}-1365.3$ to $-20.6, \mathrm{P}=0.04)$ and the interaction effect was $\beta=652.2$ ( $95 \% \mathrm{Cl}-115.4$ to $1419.9, \mathrm{P}=0.09$ ); and for left amygdala threat reactivity, the usual care effect was $\beta=-686.0$ (95\% Cl -1127.9 to $-244.1, P=0.003$ ) and the interaction effect was $\beta=664.7$ (95\% $\mathrm{Cl} 73.1$ to $1256.4, \mathrm{P}=0.03)$. In relation to energy expenditure in kilocalories per kilogram per day, for circuit dysfunction score, the usual care effect was $\beta=-4.18(95 \% \mathrm{Cl}-5.87$ to $-2.49, \mathrm{P}<0.001)$ and the interaction effect was $\beta=4.36$ (95\% Cl 2.29 to $6.43 ; P<0.001)$; for right amygdala threat reactivity, the usual care effect was $\beta=-1.82(95 \% \mathrm{Cl}-3.08$ to $-0.56, P=0.006)$ and the interaction effect was $\beta=1.94(95 \% \mathrm{Cl} 0.50$ to $3.38, P=0.01)$; and for left amygdala threat reactivity, the usual care effect was $\beta=-1.72(95 \% \mathrm{Cl}-2.51$ to $-0.93, P<0.001)$ and the interaction effect was $\beta=1.89(95 \% \mathrm{Cl} 0.84$ to $2.94, P<0.001)$.

Increased functional connectivity between the left amygdala and bilateral sgACC significantly correlated with decreased $\mathrm{BMI}$ at 6 months among intervention but not usual care participants (usual care $\beta=0.04$, $95 \% \mathrm{Cl}-0.42$ to $0.50, \mathrm{P}=0.86$; interaction $\beta=-0.61,95 \% \mathrm{Cl}-1.20$ to $-0.02, \mathrm{P}=0.04$ ) and correlated with increased servings of daily fruit and vegetable intake at 12 months among both intervention and usual care participants (usual care $\beta=1.42,95 \% \mathrm{Cl} 0.27$ to $2.57, \mathrm{P}=0.02$; interaction $\beta=-0.95,95 \% \mathrm{Cl}-2.36$ to 0.46 , $\mathrm{P}=0.18$ ) (Figure 3).

Although there was no significant intervention effect on the change in bilateral sgACC activity at 2 months (Path A), increases in this neural target were significantly correlated with dietary improvements in intervention versus usual care (Path $B$ ) for decreased grams of daily fat intake at 6 months (usual care $\beta=14.33,95 \% \mathrm{Cl} 3.53$ to $25.13, P=0.01$; interaction $\beta=-15.01,95 \% \mathrm{Cl}-29.74$ to $-0.29, P=0.046$ ), increased dietary quality scores at 6 months (usual care $\beta=-0.44,95 \% \mathrm{Cl}-0.80$ to $-0.09, P=0.01$; interaction $\beta=0.80$, $95 \% \mathrm{Cl} 0.33$ to $1.28, \mathrm{P}=0.001$ ), and increased servings of daily fruit and vegetable intake at 12 months (usual care $\beta=-1.44,95 \% \mathrm{Cl}-2.69$ to $-0.19, \mathrm{P}=0.03$; interaction $\beta=1.75,95 \% \mathrm{Cl} 0.12$ to $3.38, \mathrm{P}=0.04$ ) (Additional File 2).

\section{Neutral circuit targets engaged by sad stimuli}

Intervention effect on neural circuit targets (Path A).

There were no significant intervention effects on the neural circuit dysfunction score or any of the negative affect regions of interest related to sad stimuli at 2 months (all $P>0.05$ ).

Correlation of neural circuit targets with outcomes (Path B). 
Decreased circuit dysfunction score and bilateral amygdala activity related to sad stimuli at 2 months significantly correlated with increased calorie intake $(\mathrm{kcal} / \mathrm{d})$ at 12 months in usual care participants, but this relationship was tempered or reversed among intervention participants (Additional File 2). For circuit dysfunction score, the usual care effect was $\beta=-406.15$ (95\% Cl-743.68 to $-68.61, P=0.02)$ and the interaction effect was $\beta=460.78$ ( $95 \% \mathrm{Cl} 29.79$ to $891.77, \mathrm{P}=0.04)$; for right amygdala sad-related reactivity, the usual care effect was $\beta=-204.26(95 \% \mathrm{Cl}-377.86$ to $-30.65, P=0.02)$ and the interaction effect was $\beta=171.95$ (95\% $\mathrm{Cl}-126.91$ to $470.82, \mathrm{P}=0.25$ ); and for left amygdala sad-related reactivity, the usual care effect was $\beta=-176.84(95 \% \mathrm{Cl}-305.66$ to $-48.03, P=0.01)$ and the interaction effect was $\beta=176.90$ (95\% $\mathrm{Cl}-33.76$ to $387.56, P=0.10$ ). Meanwhile, decreased right amygdala and pregenual ACC (pACC) functional connectivity related to sad stimuli at 2 months significantly correlated with decreased calorie intake in intervention versus usual care at 6 months (usual care $\beta=-234.17,95 \% \mathrm{Cl}-488.38$ to $20.04, P=0.07$; interaction $\beta=335.85,95 \% \mathrm{Cl} 14.03$ to $657.66, P=0.04)$.

Reduced left anterior insula activity to sad stimuli at 2 months significantly correlated with improved fruit and vegetable intake in intervention versus usual care at 12 months (usual care $\beta=1.10,95 \% \mathrm{Cl} 0.81 * 10^{-4}$ to 2.19, $\mathrm{P}<0.05$; interaction $\beta=-1.80,95 \% \mathrm{Cl}-3.41$ to $-0.20, \mathrm{P}=0.03$ ) (Additional File 2).

Reduced bilateral anterior insula and pACC functional connectivity related to sad stimuli at 2 months correlated significantly with improved dietary quality in intervention versus usual care at 12 months (Right: usual care $\beta=0.81,0.005$ to $1.61, P=0.049$; interaction $\beta=-0.92$, -1.82 to $-0.03, P=0.04$; Left: usual care $\beta=0.78,0.29$ to $1.28, P=0.003$; interaction $\beta=-0.90,-1.51$ to $-0.29, P=0.005$ ) (Additional File 2). Additionally, intervention also reversed the relationship between decreased bilateral anterior insula activity to sad stimuli at 2 months and deteriorated dietary quality at 12 months in usual care, although it did not reach statistical significance (Right: usual care $\beta=0.47,95 \% \mathrm{Cl} 0.002$ to $0.94, P=0.049$; interaction $\beta=-0.69,95 \% \mathrm{Cl}-1.43$ to $0.05, P=0.07$; Left: usual care $\beta=0.66,95 \% \mathrm{Cl} 0.09$ to $1.24, P=0.02$; interaction $\beta=-0.74,-1.59$ to $0.12, P=0.09$ ).

\section{Discussion}

Using a SOBC experimental medicine approach, this investigation utilized fMRI within the context of an integrated collaborative care intervention trial to examine whether changes in negative affect circuits observed in response to early PST for depression mediated subsequent changes in diet, physical activity, and weight loss among adults with comorbid obesity and depression. The results showed some evidence of mediating effects of neural responses to threat stimuli on several outcomes. First, changes in negative affect circuit responses at 2 months (i.e., lower global circuit dysfunction scores and blunted amygdala response to threat stimuli) mediated treatment effects on physical activity and energy expenditure at 12 months. Second, increased functional connectivity between the left amygdala and bilateral sgACC related to threat stimuli at 2 months mediated treatment effects on weight loss at 6 months and fruit and vegetable intake at 12 months. Additionally, despite not showing responsiveness to PST treatment, changes at 2 months in some circuits (e.g., bilateral amygdala, bilateral anterior insula, functional connectivity between pACC and bilateral anterior insula) related to sad stimuli were significantly 
correlated with changes in dietary behaviors (i.e., calorie intake, fruit and vegetable intake, and dietary quality as measured by DASH score) at 12 months. Cumulatively, these findings suggest improvements in weight loss and related health behaviors during integrated behavior therapy for comorbid obesity and depression may depend on early changes in neural circuits that process negative affect. Also, since threat was evoked in the non-conscious viewing condition, the relatively consistent mediating effects of neural responses engaged by threat across outcomes suggest that non-conscious factors, which may affect program adherence, should be further explored in future research on behavioral weight loss treatments.

This study showed that initial PST for depression during the integrated collaborative care intervention improved the amygdala activity to threat stimuli among intervention versus control participants by 2 months. Activity in the amygdala is critical for affective responses to negative stimuli and is altered by depression (5). As such, attenuated threat reactivity in the bilateral amygdala and improved amgydalasgACC functional connectivity observed in the intervention group relative to usual care at 2 months may represent the neural signature of a successful response to PST that mediates subsequent changes in physical activity, fruit and vegetable intake, and weight loss through 12 months. In line with the SOBC experimental medicine approach, this demonstrated effective engagement with the hypothesized neural targets that are associated with treatment effects.

To our knowledge, this is the first study to identify bilateral amygdala activity to threat stimuli as a mediator of subsequent improvements in physical activity and energy expenditure. Much of the literature to date has focused on identifying the ability of behavior (e.g., acute exercise (45)) and lifestyle interventions (e.g., tai chi, exercise training, weight loss program) to engage neural circuits of interest (4649). These prior studies suggest that certain interventions can selectively activate or inhibit neural targets (e.g., default mode, attention/limbic, and executive control networks), but these observations have not been connected to changes in health outcomes. Some data suggest that baseline brain network modularity (i.e., the degree to which a group of neural components are partitioned into subnetworks) (50) may predict individuals' changes in executive/working memory function following cognitive (51) or exercise training interventions $(52,53)$. Little data to date, however, has connected changes in neural target activation from a behavioral intervention with longitudinal changes in health behavior or outcomes. This study suggests that reducing amygdala activity to non-conscious threat stimuli at an early stage through targeted intervention can impact longitudinal changes in physical activity and energy expenditure. Improvements in non-conscious threat-related amygdala reactivity may improve how individuals subconsciously respond to stressors or barriers that limit physical activity (e.g., family/work stress, neighborhood safety, and time availability) (12).

The neuroimaging results identified additional regions that might be potential mediators of change in weight and eating behaviors (e.g., bilateral amygdala, bilateral anterior insula, and functional connectivity between pACC and bilateral anterior insula). These neural circuits are notable for being involved in emotional processing (54). Individuals with obesity may require greater effort to inhibit craving of pleasant but unhealthy foods (e.g., high calorie or high fat foods), especially in an emotional context (55). In addition, insula is directly involved in interoception and changes in insula activity could reflect actual 
changes in perception of internal state (such as hunger vs. fullness/satiety) (56). Although the initial PST for depression in this study may not be potent enough to engage these sad-related neural targets, interventions optimized with strategies to target these circuits may help reduce vulnerability to emotional eating in negative emotional (e.g. sad) states or hypersensitivity to interoceptive signals of hunger, thus promoting weight loss or preventing weight gain among individuals with comorbid obesity and depression. Although our study did not support the hypothesized mediation pathway of these neural circuits (i.e., requiring both Path $A$ and $B$ exist), there is previous evidence supporting each path separately. Prior RCTs of behavioral weight loss or weight gain prevention interventions found that targeted intervention strategies (e.g., cognitive reappraisal, food response and attention training) significantly reduced specific region responses (e.g., left mid cingulate cortex, mid insula) $(57,58)$. Prior studies using functional brain imaging with food stimuli have also identified links between some of the same neural circuits (e.g., amygdala, insula, ACC) and eating behaviors (e.g., overeating and food craving) and obesity or weight gain $(59,60)$. Future studies of behavioral interventions optimized with strategies to engage these neural circuits are needed to confirm their utility in improving eating behaviors and weight loss.

This study has several limitations. First, given this was a pilot study with a small sample, the findings are hypothesis generating, with more research needed to replicate and extend the results. Second, although the self-report measures of physical activity and diet in this study have been validated and widely used in behavioral studies, they may be vulnerable to individuals' ability to recall such behaviors correctly. As such, the 7-day physical activity recall and single, multiple pass 24-hour dietary recall may not have been able to accurately capture some of the changes that participants made, thereby limiting our ability to detect significant mediation if it was indeed present. Future studies could employ objective assessments of physical activity via accelerometry and repeat measures of dietary intake via multiple 24-hour dietary recalls. Third, the ENGAGE participants were primarily women, non-Hispanic White, and college educated. Replication and assessment of generalizability in independent samples with more diverse sex, racial/ethnic, and socioeconomic distributions is an important next step in generalizing these findings to a broader population. Last, that ENGAGE participants were a subsample of the parent RAINBOW trial may limit the net benefit of the random assignment based on Pocock's covariate-adaptive minimization.

Moving forward, identifying neural targets that play a role in the mechanism of behavioral weight loss interventions offers a new pathway for intervention optimization and advances the SOBC through an experimental medicine approach (61). The consistent mediating effects of non-conscious threat-evoked neural responses across outcomes suggest that future interventions may be optimized by including strategies that target non-conscious emotion regulation for behavior change. To facilitate this, including wearable passive sensing devices for measurements that do not rely on consciously engaged reporting of emotion and behavior by the respondent may hold promise. Speculatively, the attenuation of threat dysregulation and reactivity at the amygdala level may also be related to inflammatory processes. Acute inflammation has been shown to increase amygdala activity to socially threatening images (62) and reduce amygdala-sgACC functional connectivity (63). Further investigation of neuroinflammation in disease activity and treatment response in obesity and depression is warranted. Additionally, future 
research on behavioral interventions that engage the negative affect circuit (e.g., the hypothesized sadrelated neural circuits) may inform intervention optimization in obesity combined with depression. For example, future studies may investigate whether behavioral interventions enhanced with strategies for eating disorders (e.g., mindfulness-based emotional eating awareness training $(64,65)$, acceptance and commitment therapy (66)) engage the hypothesized sad-related circuits (e.g., amygdala, anterior insula) and whether changes in these circuits mediated the changes in eating behaviors and weight.

\section{Conclusion}

This study found lower circuit dysfunction scores and blunted amygdala response to threat stimuli, as well as improved functional connectivity between left amygdala and bilateral sgACC in response to initial PST for depression significantly mediated later changes in physical activity, BMI, and fruit/vegetable intake. Overall, these results shed light on the neural mechanisms underlying behavior therapy in obesity with comorbid depression and provide new directions for future intervention.

\section{Abbreviations}

ACC Anterior Cingulate Cortex

$\mathrm{Cl}$ Confidence Interval

DASH Dietary Approach to Stop Hypertension

EHR Electronic Health Records

fMRI functional Magnetic Resonance Imaging

GLB Group Lifestyle Balance

I-CARE Integrated Coaching for Better Mood and Weight

MET Metabolic Equivalent Task

NDSR Nutrition Data System for Research

pACC pregenual ACC

PHQ-9 9-item Patient Health Questionnaire

PPI Psychophysiological Interaction

PST Problem Solving Therapy

RAINBOW Research Aimed at Improving Both Mood and Weight 
sgACC subgenual ACC

SOBC Science of Behavior Change

US United States

\section{Declarations}

\section{Ethics approval and consent to participate}

The Institutional Review Boards for the University of Illinois at Chicago and the Stanford University approved the study. All participants provided written informed consent.

\section{Consent for publication}

Not applicable.

\section{Availability of data and materials}

The datasets used and/or analyzed during the current study are available from the corresponding author only under a formal data sharing and use agreement that provides for a commitment to the following: (1) using the data only for research purposes and not to identify any individual participant, (2) securing the data using appropriate computer technology, (3) destroying or returning the data after analyses are completed, (4) accepting reporting responsibilities, (5) abiding by restrictions on redistribution of the data for commercial purposes or to third parties, and (6) proper acknowledgement of the data resource. In addition, appropriate fees may be assessed upon mutual agreement on requests for information in a format other than that we intend to provide. We will not be responsible for providing any analytical support.

\section{Competing interests}

JM is a paid scientific consultant for Health Mentor, Inc. (San Jose, CA). LMW is on the Scientific Advisory Board for One Mind Psyberguide and the External Advisory Board for the Laureate Institute for Brain Research. OAA is the co-founder of Keywise Al and the servers on the advisory boards of Blueprint Health and Embodied Labs.

\section{Funding}

This work is supported by the National Institutes of Health $(\mathrm{NIH})$ Science of Behavior Change Common Fund Program through an award administered by the National Heart, Lung, and Blood Institute grant number UH2HL132368 and UH3HL132368. The RAINBOW trial was supported by the National Heart, Lung, And Blood Institute of the NIH under Award Number R01HL119453. The content is solely the responsibility of the authors and does not necessarily represent the official views of the National Heart, Lung and Blood Institute or the National Institutes of Health. No sponsor or funding source has a role in 
the design or conduct of the study; collection, management, analysis or interpretation of the data; or preparation, review or approval of the manuscript.

\section{Authors' contributions}

$\mathrm{NL}$ and WKL drafted the manuscript. JM and LMW conceived the study, led the study design and conduct, obtained funding, and has the overall responsibility for its design and conduct. PWL, JMS, JMS, ANG, JW, PS, EMV, MBS, LX, LGR, TS contributed to the study design and conduct. PWL, LX, ANG, JW contributed to planning the statistical analyses. All authors contributed to drafting the manuscript and/or participated in critical revisions for important intellectual content.

\section{Acknowledgements}

The authors extend special thanks to the RAINBOW and ENGAGE participants and their families who make this study possible. The authors also thank the RAINBOW and ENGAGE Data and Safety Monitoring Board members (William L. Haskell, PhD, Manisha Desai, PhD, Mickey Trockel, MD, Manpreet K. Singh, MD, MS, Sandra Tsai, MD, and Alex Leow, MD, PhD), and the study team members who have made substantial contributions to the conduct of the study or to data acquisition and analyses.

\section{References}

1. Hales CM, Carroll MD, Fryar CD, Ogden CL. Prevalence of obesity among adults and youth: United States, 2015-2016: US Department of Health and Human Services, Centers for Disease Control and Prevention, National Center for Health Statistics; 2017.

2. Pereira-Miranda E, Costa PRF, Queiroz VAO, Pereira-Santos M, Santana MLP. Overweight and Obesity Associated with Higher Depression Prevalence in Adults: A Systematic Review and Meta-Analysis. J Am Coll Nutr. 2017;36(3):223-33.

3. Ladwig KH, Marten-Mittag B, Lowel H, Doring A, Wichmann HE. Synergistic effects of depressed mood and obesity on long-term cardiovascular risks in 1510 obese men and women: results from the MONICA-KORA Augsburg Cohort Study 1984-1998. Int J Obes (Lond). 2006;30(9):1408-14.

4. Park BY, Hong J, Park H. Neuroimaging biomarkers to associate obesity and negative emotions. Sci Rep. 2017;7(1):7664.

5. Jaworska N, Yang XR, Knott V, MacQueen G. A review of fMRI studies during visual emotive processing in major depressive disorder. The world journal of biological psychiatry : the official journal of the World Federation of Societies of Biological Psychiatry. 2015;16(7):448-71.

6. Sainsbury K, Evans EH, Pedersen S, Marques MM, Teixeira PJ, Lahteenmaki L, et al. Attribution of weight regain to emotional reasons amongst European adults with overweight and obesity who regained weight following a weight loss attempt. Eat Weight Disord. 2019;24(2):351-61.

7. Farr OM, Li CR, Mantzoros CS. Central nervous system regulation of eating: Insights from human brain imaging. Metabolism. 2016;65(5):699-713. 
8. Raman J, Smith E, Hay P. The clinical obesity maintenance model: an integration of psychological constructs including mood, emotional regulation, disordered overeating, habitual cluster behaviours, health literacy and cognitive function. J Obes. 2013;2013:240128.

9. Czepczor-Bernat K, Brytek-Matera A, Gramaglia C, Zeppegno P. The moderating effects of mindful eating on the relationship between emotional functioning and eating styles in overweight and obese women. Eat Weight Disord. 2019.

10. van Strien T. Causes of Emotional Eating and Matched Treatment of Obesity. Curr Diab Rep. 2018;18(6):35.

11. Whiteside U, Chen E, Neighbors C, Hunter D, Lo T, Larimer M. Difficulties regulating emotions: Do binge eaters have fewer strategies to modulate and tolerate negative affect? Eat Behav. 2007;8(2):162-9.

12. Stults-Kolehmainen MA, Sinha R. The effects of stress on physical activity and exercise. Sports medicine (Auckland, NZ). 2014;44(1):81-121.

13. Ma J, Rosas LG, Lv N, Xiao L, Snowden MB, Venditti EM, et al. Effect of Integrated Behavioral Weight Loss Treatment and Problem-Solving Therapy on Body Mass Index and Depressive Symptoms Among Patients With Obesity and Depression: The RAINBOW Randomized Clinical Trial. JAMA. 2019;321(9):869-79.

14. Lv N, Xiao L, Majd M, Lavori PW, Smyth JM, Rosas LG, et al. Variability in engagement and progress in efficacious integrated collaborative care for primary care patients with obesity and depression: Within-treatment analysis in the RAINBOW trial. PloS one. 2020;15(4):e0231743.

15. Ochsner KN, Silvers JA, Buhle JT. Functional imaging studies of emotion regulation: a synthetic review and evolving model of the cognitive control of emotion. Ann N Y Acad Sci. 2012;1251:E1-24.

16. Korgaonkar MS, Erlinger M, Breukelaar IA, Boyce P, Hazell P, Antees C, et al. Amygdala Activation and Connectivity to Emotional Processing Distinguishes Asymptomatic Patients With Bipolar Disorders and Unipolar Depression. Biol Psychiatry Cogn Neurosci Neuroimaging. 2019;4(4):361-70.

17. Williams LM. Precision psychiatry: a neural circuit taxonomy for depression and anxiety. Lancet Psychiatry. 2016;3(5):472-80.

18. Williams LM. Defining biotypes for depression and anxiety based on large-scale circuit dysfunction: a theoretical review of the evidence and future directions for clinical translation. Depress Anxiety. 2017;34(1):9-24.

19. Matthews SC, Strigo IA, Simmons AN, Yang TT, Paulus MP. Decreased functional coupling of the amygdala and supragenual cingulate is related to increased depression in unmedicated individuals with current major depressive disorder. J Affect Disord. 2008;111(1):13-20.

20. Gorka SM, Young CB, Klumpp H, Kennedy AE, Francis J, Ajilore O, et al. Emotion-based brain mechanisms and predictors for SSRI and CBT treatment of anxiety and depression: a randomized trial. Neuropsychopharmacology. 2019;44(9):1639-48.

21. Franklin G, Carson AJ, Welch KA. Cognitive behavioural therapy for depression: systematic review of imaging studies. Acta Neuropsychiatr. 2016;28(2):61-74. 
22. Williams LM, Korgaonkar MS, Song YC, Paton R, Eagles S, Goldstein-Piekarski A, et al. Amygdala Reactivity to Emotional Faces in the Prediction of General and Medication-Specific Responses to Antidepressant Treatment in the Randomized iSPOT-D Trial. Neuropsychopharmacology. 2015;40(10):2398-408.

23. Williams LM, Pines A, Goldstein-Piekarski AN, Rosas LG, Kullar M, Sacchet MD, et al. The ENGAGE study: Integrating neuroimaging, virtual reality and smartphone sensing to understand self-regulation for managing depression and obesity in a precision medicine model. Behav Res Ther. 2018;101:5870.

24. Ma J, Yank V, Lv N, Goldhaber-Fiebert JD, Lewis MA, Kramer MK, et al. Research aimed at improving both mood and weight (RAINBOW) in primary care: A type 1 hybrid design randomized controlled trial. Contemp Clin Trials. 2015;43:260-78.

25. Xiao L, Huang Q, Yank V, Ma J. An easily accessible Web-based minimization random allocation system for clinical trials. J Med Internet Res. 2013;15(7):e139.

26. Pocock SJ, Simon R. Sequential treatment assignment with balancing for prognostic factors in the controlled clinical trial. Biometrics. 1975;31(1):103-15.

27. Kramer MK, Kriska AM, Venditti EM, Miller RG, Brooks MM, Burke LE, et al. Translating the Diabetes Prevention Program: a comprehensive model for prevention training and program delivery. Am J Prev Med. 2009;37(6):505-11.

28. Ciechanowski P, Wagner E, Schmaling K, Schwartz S, Williams B, Diehr P, et al. Community-integrated home-based depression treatment in older adults: a randomized controlled trial. JAMA. 2004;291(13):1569-77.

29. Ciechanowski P, Chaytor N, Miller J, Fraser R, Russo J, Unutzer J, et al. PEARLS depression treatment for individuals with epilepsy: a randomized controlled trial. Epilepsy Behav. 2010;19(3):225-31.

30. Measures from the PhenX Toolkit version February 4 2011, Ver 4.2 (www.phenxtoolkit.org). PhenX (consensus measures of Phenotypes and eXposures) is supported by NHGRI award No. U01 HG004597 [

31. Blair SN, Haskell WL, Ho P, Paffenbarger RS, Jr., Vranizan KM, Farquhar JW, et al. Assessment of habitual physical activity by a seven-day recall in a community survey and controlled experiments. Am J Epidemiol. 1985;122(5):794-804.

32. Conway JM, Ingwersen LA, Vinyard BT, Moshfegh AJ. Effectiveness of the US Department of Agriculture 5-step multiple-pass method in assessing food intake in obese and nonobese women. Am J Clin Nutr. 2003;77(5):1171-8.

33. Conway JM, Ingwersen LA, Moshfegh AJ. Accuracy of dietary recall using the USDA five-step multiple-pass method in men: an observational validation study. J Am Diet Assoc. 2004;104(4):595603.

34. Fung TT, Chiuve SE, McCullough ML, Rexrode KM, Logroscino G, Hu FB. Adherence to a DASH-style diet and risk of coronary heart disease and stroke in women. Arch Intern Med. 2008;168(7):713-20. 
35. Sacks FM, Obarzanek E, Windhauser MM, Svetkey LP, Vollmer WM, McCullough M, et al. Rationale and design of the Dietary Approaches to Stop Hypertension trial (DASH). A multicenter controlledfeeding study of dietary patterns to lower blood pressure. Ann Epidemiol. 1995;5(2):108-18.

36. Sacks FM, Svetkey LP, Vollmer WM, Appel LJ, Bray GA, Harsha D, et al. Effects on blood pressure of reduced dietary sodium and the Dietary Approaches to Stop Hypertension (DASH) diet. DASHSodium Collaborative Research Group. N Engl J Med. 2001;344(1):3-10.

37. Sallis JF, Haskell WL, Wood PD, Fortmann SP, Rogers T, Blair SN, et al. Physical activity assessment methodology in the Five-City Project. Am J Epidemiol. 1985;121(1):91-106.

38. Wilson PW, Paffenbarger RS, Jr., Morris JN, Havlik RJ. Assessment methods for physical activity and physical fitness in population studies: report of a NHLBI workshop. Am Heart J. 1986;111(6):117792.

39. Korgaonkar MS, Grieve SM, Etkin A, Koslow SH, Williams LM. Using standardized fMRI protocols to identify patterns of prefrontal circuit dysregulation that are common and specific to cognitive and emotional tasks in major depressive disorder: first wave results from the iSPOT-D study. Neuropsychopharmacology. 2013;38(5):863-71.

40. Goldstein-Piekarski AN, Korgaonkar MS, Green E, Suppes T, Schatzberg AF, Hastie T, et al. Human amygdala engagement moderated by early life stress exposure is a biobehavioral target for predicting recovery on antidepressants. Proc Natl Acad Sci U S A. 2016;113(42):11955-60.

41. Goldstein-Piekarski AN, Ball TM, Samara Z, Staveland BR, Fleming SL, Grisanzio KA, et al. Mapping neural circuit biotypes to symptoms and behavioral dimensions of depression and anxiety. Lancet Psychiatry [In Prep].

42. Friston KJ, Buechel C, Fink GR, Morris J, Rolls E, Dolan RJ. Psychophysiological and modulatory interactions in neuroimaging. Neurolmage. 1997;6(3):218-29.

43. Kraemer HC, Wilson GT, Fairburn CG, Agras WS. Mediators and moderators of treatment effects in randomized clinical trials. Arch Gen Psychiatry. 2002;59(10):877-83.

44. Althouse AD. Adjust for Multiple Comparisons? It's Not That Simple. Ann Thorac Surg. 2016;101(5):1644-5.

45. Weng TB, Pierce GL, Darling WG, Falk D, Magnotta VA, Voss MW. The Acute Effects of Aerobic Exercise on the Functional Connectivity of Human Brain Networks. Brain plasticity (Amsterdam, Netherlands). 2017;2(2):171-90.

46. Liu Z, Wu Y, Li L, Guo X. Functional Connectivity Within the Executive Control Network Mediates the Effects of Long-Term Tai Chi Exercise on Elders' Emotion Regulation. Frontiers in aging neuroscience. 2018;10:315.

47. Cornier MA, Melanson EL, Salzberg AK, Bechtell JL, Tregellas JR. The effects of exercise on the neuronal response to food cues. Physiology \& behavior. 2012;105(4):1028-34.

48. McFadden KL, Cornier MA, Melanson EL, Bechtell JL, Tregellas JR. Effects of exercise on restingstate default mode and salience network activity in overweight/obese adults. Neuroreport. 2013;24(15):866-71. 
49. Mokhtari F, Rejeski WJ, Zhu Y, Wu G, Simpson SL, Burdette JH, et al. Dynamic fMRI networks predict success in a behavioral weight loss program among older adults. Neurolmage. 2018;173:421-33.

50. Gallen CL, D'Esposito M. Brain Modularity: A Biomarker of Intervention-related Plasticity. Trends Cogn Sci. 2019;23(4):293-304.

51. Baniqued PL, Gallen CL, Voss MW, Burzynska AZ, Wong CN, Cooke GE, et al. Brain Network Modularity Predicts Exercise-Related Executive Function Gains in Older Adults. Frontiers in aging neuroscience. 2017;9:426.

52. Gallen CL, Baniqued PL, Chapman SB, Aslan S, Keebler M, Didehbani N, et al. Modular Brain Network Organization Predicts Response to Cognitive Training in Older Adults. PloS one. 2016;11(12):e0169015.

53. Arnemann KL, Chen AJ, Novakovic-Agopian T, Gratton C, Nomura EM, D'Esposito M. Functional brain network modularity predicts response to cognitive training after brain injury. Neurology. 2015;84(15):1568-74.

54. Nomi JS, Schettini E, Broce I, Dick AS, Uddin LQ. Structural Connections of Functionally Defined Human Insular Subdivisions. Cereb Cortex. 2018;28(10):3445-56.

55. Wang GJ, Shokri Kojori E, Yuan K, Wiers CE, Manza P, Wong CT, et al. Inhibition of food craving is a metabolically active process in the brain in obese men. Int J Obes (Lond). 2020;44(3):590-600.

56. Simmons WK, DeVille DC. Interoceptive contributions to healthy eating and obesity. Curr Opin Psychol. 2017;17:106-12.

57. Stice E, Yokum S, Burger K, Rohde P, Shaw H, Gau JM. A pilot randomized trial of a cognitive reappraisal obesity prevention program. Physiology \& behavior. 2015;138:124-32.

58. Stice E, Yokum S, Veling H, Kemps E, Lawrence NS. Pilot test of a novel food response and attention training treatment for obesity: Brain imaging data suggest actions shape valuation. Behav Res Ther. 2017;94:60-70.

59. Monteleone AM, Castellini G, Volpe U, Ricca V, Lelli L, Monteleone P, et al. Neuroendocrinology and brain imaging of reward in eating disorders: A possible key to the treatment of anorexia nervosa and bulimia nervosa. Prog Neuropsychopharmacol Biol Psychiatry. 2018;80(Pt B):132-42.

60. Stice E, Figlewicz DP, Gosnell BA, Levine AS, Pratt WE. The contribution of brain reward circuits to the obesity epidemic. Neurosci Biobehav Rev. 2013;37(9 Pt A):2047-58.

61. Nielsen L, Riddle M, King JW, Team NIHSoBCl, Aklin WM, Chen W, et al. The NIH Science of Behavior Change Program: Transforming the science through a focus on mechanisms of change. Behav Res Ther. 2018;101:3-11.

62. Inagaki TK, Muscatell KA, Irwin MR, Cole SW, Eisenberger NI. Inflammation selectively enhances amygdala activity to socially threatening images. Neurolmage. 2012;59(4):3222-6.

63. Harrison NA, Brydon L, Walker C, Gray MA, Steptoe A, Critchley HD. Inflammation causes mood changes through alterations in subgenual cingulate activity and mesolimbic connectivity. Biological psychiatry. 2009;66(5):407-14. 
64. Lattimore P. Mindfulness-based emotional eating awareness training: taking the emotional out of eating. Eat Weight Disord. 2019.

65. Katterman SN, Kleinman BM, Hood MM, Nackers LM, Corsica JA. Mindfulness meditation as an intervention for binge eating, emotional eating, and weight loss: a systematic review. Eat Behav. 2014;15(2):197-204.

66. Jarvela-Reijonen E, Karhunen L, Sairanen E, Muotka J, Lindroos S, Laitinen J, et al. The effects of acceptance and commitment therapy on eating behavior and diet delivered through face-to-face contact and a mobile app: a randomized controlled trial. Int J Behav Nutr Phys Act. 2018;15(1):22.

\section{Tables}

Table 1. Baseline Characteristics by Treatment Group 


\begin{tabular}{|c|c|c|c|}
\hline & $\begin{array}{l}\text { Combined } \\
(n=108)\end{array}$ & $\begin{array}{l}\text { Intervention } \\
(\mathrm{n}=59)\end{array}$ & $\begin{array}{l}\text { Usual Care } \\
(n=49)\end{array}$ \\
\hline \multicolumn{4}{|l|}{ Clinics in the Bay Area, No. $(\%)^{a}$} \\
\hline Los Altos & $3(3)$ & $2(3)$ & $1(2)$ \\
\hline Sunnyvale & $6(6)$ & $3(5)$ & $3(6)$ \\
\hline Palo Alto & $65(60)$ & $36(61)$ & $29(59)$ \\
\hline Mountain View & $34(31)$ & $18(31)$ & $16(33)$ \\
\hline Age, mean $(S D)^{a}$ & $52.0(11.7)$ & $52.4(11.6)$ & $51.6(12.0)$ \\
\hline \multicolumn{4}{|l|}{ Sex, No. $(\%)^{a}$} \\
\hline Female & $73(68)$ & $42(71)$ & $31(63)$ \\
\hline Male & $35(32)$ & $17(29)$ & $18(37)$ \\
\hline \multicolumn{4}{|l|}{ Race/ethnicity, No. (\%) ${ }^{a}$} \\
\hline Non-Hispanic White & $81(75)$ & $46(78)$ & 35 (71) \\
\hline Black & $1(1)$ & $1(2)$ & $0(0)$ \\
\hline Asian/Pacific Islander & $8(7)$ & $5(8)$ & $3(6)$ \\
\hline Hispanic & $11(10)$ & $4(7)$ & $7(14)$ \\
\hline Other ${ }^{b}$ & $7(6)$ & $3(5)$ & $4(8)$ \\
\hline \multicolumn{4}{|l|}{ Education, No. (\%) ${ }^{a}$} \\
\hline High school graduate or GED & $6(6)$ & $2(3)$ & $4(8)$ \\
\hline Some college & $24(22)$ & $10(17)$ & $14(29)$ \\
\hline Undergraduate degree & $43(40)$ & $28(47)$ & $15(31)$ \\
\hline Graduate level work or degree & $35(32)$ & $19(32)$ & $16(33)$ \\
\hline \multicolumn{4}{|l|}{ Body mass index, mean (SD) ${ }^{a}$} \\
\hline Both sexes & $35.5(5.1)$ & $34.9(5.2)$ & $36.3(4.9)$ \\
\hline Women & $36.2(5.5)$ & $35.2(5.5)$ & $37.6(5.2)$ \\
\hline Men & $34.1(3.8)$ & $34.2(4.2)$ & $34.0(3.5)$ \\
\hline \multicolumn{4}{|l|}{ Weight, mean (SD), kg } \\
\hline Both sexes & $101.2(15.6)$ & $98.8(17.1)$ & $104.2(13.2)$ \\
\hline
\end{tabular}




\begin{tabular}{|c|c|c|c|}
\hline Women & $97.3(15.4)$ & $94.7(16.5)$ & $100.8(13.4)$ \\
\hline Men & $109.4(12.6)$ & $108.9(14.5)$ & $109.9(11.0)$ \\
\hline \multicolumn{4}{|l|}{ Height, mean (SD), cm } \\
\hline Both sexes & $168.8(10.3)$ & $168.1(10.1)$ & $169.8(10.6)$ \\
\hline Women & $163.9(7.8)$ & $163.9(8.4)$ & $163.8(7.2)$ \\
\hline Men & $179.2(6.4)$ & $178.4(5.7)$ & $180.0(7.0)$ \\
\hline 9-item Patient Health Questionnaire $(S D)^{c}$ & $13.7(3.0)$ & $14.0(3.1)$ & $13.4(2.9)$ \\
\hline 20-item Depression Symptom Checklist score (SD) $)^{\mathrm{a}, \mathrm{d}}$ & $1.5(0.5)$ & $1.5(0.6)$ & $1.6(0.5)$ \\
\hline 7-Item Generalized Anxiety Disorder scale score $(S D)^{e}$ & $7.9(4.6)$ & $7.8(4.3)$ & $8.02(5.0)$ \\
\hline Taking antidepressant medications, No. (\%) ${ }^{\mathrm{a}, \mathrm{f}}$ & $43(40)$ & $24(41)$ & $19(39)$ \\
\hline Hospitalized during the last year, No. (\%) $)^{a, f}$ & $11(10)$ & $7(12)$ & $4(8)$ \\
\hline Depression diagnosis or treatment, No. (\%) & $72(67)$ & $39(66)$ & $33(67)$ \\
\hline \multicolumn{4}{|l|}{ Employment status, No. (\%) } \\
\hline Full-time & $62(57)$ & $34(58)$ & $28(57)$ \\
\hline Part-time & $15(14)$ & $10(17)$ & $5(10)$ \\
\hline Unemployed & $31(29)$ & $15(25)$ & $16(33)$ \\
\hline \multicolumn{4}{|l|}{ Income, No./total (\%) } \\
\hline$<\$ 75000$ & 23/99 (23) & $8 / 53(15)$ & $15 / 46(33)$ \\
\hline$\$ 75000-\$ 150000$ & $34 / 99(34)$ & $21 / 53(40)$ & $13 / 46(28)$ \\
\hline$>=150000$ & $42 / 99(42)$ & $24 / 53(45)$ & $18 / 46(39)$ \\
\hline \multicolumn{4}{|l|}{ Insurance, №. (\%) } \\
\hline Preferred provider organization & $69(64)$ & $42(71)$ & $27(55)$ \\
\hline Health management organization & $30(28)$ & $12(20)$ & $18(37)$ \\
\hline Medicare fee for service & $7(6)$ & $5(8)$ & $2(4)$ \\
\hline Other Insurance & $2(2)$ & $0(0)$ & $2(4)$ \\
\hline \multicolumn{4}{|l|}{ Marital status, No. (\%) } \\
\hline Married or living with a partner & $65(60)$ & $35(59)$ & $30(61)$ \\
\hline Single, separated, divorced, or widowed & $43(40)$ & $24(41)$ & $19(39)$ \\
\hline
\end{tabular}




\begin{tabular}{|llll|}
\hline$<2$ & $21(19)$ & $14(24)$ & $7(14)$ \\
\hline 2 & $43(40)$ & $23(39)$ & $20(41)$ \\
\hline$>=3$ & $44(41)$ & $22(37)$ & $22(45)$ \\
\hline
\end{tabular}

a Randomization balancing factors.

${ }^{b}$ Includes 1 participants reporting mixed race and 2 reporting other race (unspecified) in the intervention group; 4 participants reporting mixed race in the usual care control group.

${ }^{\mathrm{C}} \mathrm{PHQ}-9$, total scores of the 9 items with a range from 0 (no symptoms) to 27 (most severe symptoms). PHQ-9 cutoff points of 10,15 , and 20 correspond to moderate, moderately severe, and severe depression, respectively.

${ }^{d}$ SCL-20, total average scores of the 20 items with a range from 0 (not at all) to 4 (extremely). SCL-20 cutoff points of 1.5 and 2.0 correspond to moderate and severe depression, respectively.

e GAD-7, total scores of the 7 items with a range from 0 (no symptoms) to 21 (most severe symptoms). GAD-7 cutoff points of 5, 10, and 15 correspond to mild, moderate, and severe anxiety, respectively.

${ }^{f}$ Based on patient self-report at screening.

Table 2. Treatment Effects on the Potential Mediators (Path A) 


\begin{tabular}{|c|c|c|c|c|c|c|c|}
\hline \multirow[t]{2}{*}{ Circuit } & \multirow[t]{3}{*}{ Hemi. } & \multirow{2}{*}{\multicolumn{2}{|c|}{$\begin{array}{l}\text { Intervention } \\
\text { Unadjusted } \\
\text { Estimates, mean } \\
\text { (SD) }\end{array}$}} & \multirow{2}{*}{\multicolumn{2}{|c|}{$\begin{array}{l}\text { Usual Care } \\
\text { Unadjusted } \\
\text { Estimates, mean } \\
\text { (SD) }\end{array}$}} & \multirow{2}{*}{\multicolumn{2}{|c|}{$\begin{array}{l}\text { Intervention } \\
\text { Difference }\end{array}$}} \\
\hline & & & & & & & \\
\hline $\begin{array}{l}\text { Neural } \\
\text { Target }\end{array}$ & & Baseline & $\begin{array}{l}2 \\
\text { months }\end{array}$ & Baseline & $\begin{array}{l}2 \\
\text { months }\end{array}$ & $\begin{array}{l}\text { Coefficient } \\
(95 \% \mathrm{Cl})\end{array}$ & $P$ \\
\hline \multicolumn{8}{|l|}{ Threat (non-conscious) } \\
\hline $\begin{array}{l}\text { Circuit } \\
\text { dysfunction }\end{array}$ & - & $\begin{array}{l}0.15 \\
(0.45)\end{array}$ & $\begin{array}{l}-0.26 \\
(0.68)\end{array}$ & $\begin{array}{l}-0.13 \\
(0.63)\end{array}$ & $\begin{array}{l}0.27 \\
(0.86)\end{array}$ & $\begin{array}{l}-0.53 \\
(-0.93 \\
-0.13)\end{array}$ & 0.01 \\
\hline \multirow[t]{2}{*}{ Amygdala } & L & $\begin{array}{l}0.41 \\
(1.04)\end{array}$ & $\begin{array}{l}-0.32 \\
(1.23)\end{array}$ & $\begin{array}{l}0.12 \\
(1.15)\end{array}$ & $\begin{array}{l}0.54 \\
(1.71)\end{array}$ & $\begin{array}{l}-0.86 \\
(-1.63 \\
-0.10)\end{array}$ & 0.03 \\
\hline & $\mathrm{R}$ & $\begin{array}{l}0.23 \\
(0.77)\end{array}$ & $\begin{array}{l}-0.07 \\
(1.44)\end{array}$ & $\begin{array}{l}-0.11 \\
(1.01)\end{array}$ & $\begin{array}{l}0.76 \\
(1.24)\end{array}$ & $\begin{array}{l}-0.83 \\
(-1.55 \\
-0.11)\end{array}$ & 0.02 \\
\hline SgACC & B & $\begin{array}{l}0.47 \\
(1.09)\end{array}$ & $\begin{array}{l}0.19 \\
(1.17)\end{array}$ & $\begin{array}{l}0.04 \\
(1.07)\end{array}$ & $\begin{array}{l}0.52 \\
(1.24)\end{array}$ & $\begin{array}{l}-0.33 \\
(-0.96 \\
0.30)\end{array}$ & 0.30 \\
\hline \multirow[t]{2}{*}{$\begin{array}{l}\text { sgACC to } \\
\text { Amygdala }\end{array}$} & $B-L$ & $\begin{array}{l}-0.35 \\
(0.91)\end{array}$ & $\begin{array}{l}0.39 \\
(1.44)\end{array}$ & $\begin{array}{l}0.34 \\
(1.07)\end{array}$ & $\begin{array}{l}-0.39 \\
(1.33)\end{array}$ & $\begin{array}{l}0.78(0.05 \\
1.52)\end{array}$ & 0.04 \\
\hline & $B-R$ & $\begin{array}{l}-0.25 \\
(0.80)\end{array}$ & $\begin{array}{l}0.34 \\
(1.12)\end{array}$ & $\begin{array}{l}0.24 \\
(0.92)\end{array}$ & $\begin{array}{l}-0.16 \\
(1.31)\end{array}$ & $\begin{array}{l}0.50 \\
(-0.14 \\
1.13)\end{array}$ & 0.12 \\
\hline \multicolumn{8}{|l|}{ Sad (conscious) } \\
\hline $\begin{array}{l}\text { Circuit } \\
\text { dysfunction }\end{array}$ & - & $\begin{array}{l}-0.18 \\
(0.41)\end{array}$ & $\begin{array}{l}0.01 \\
(0.70)\end{array}$ & $\begin{array}{l}-0.30 \\
(0.53)\end{array}$ & $\begin{array}{l}0.06 \\
(0.61)\end{array}$ & $\begin{array}{l}-0.05 \\
(-0.39 \\
0.29)\end{array}$ & 0.78 \\
\hline \multirow[t]{2}{*}{ Amygdala } & L & $\begin{array}{l}-0.37 \\
(1.00)\end{array}$ & $\begin{array}{l}-0.08 \\
(1.23)\end{array}$ & $\begin{array}{l}-0.53 \\
(1.00)\end{array}$ & $\begin{array}{l}0.08 \\
(1.57)\end{array}$ & $\begin{array}{l}-0.16 \\
(-0.87 \\
0.55)\end{array}$ & 0.65 \\
\hline & $\mathrm{R}$ & $\begin{array}{l}-0.15 \\
(0.77)\end{array}$ & $\begin{array}{l}-0.04 \\
(1.09)\end{array}$ & $\begin{array}{l}-0.28 \\
(0.95)\end{array}$ & $\begin{array}{l}0.18 \\
(1.24)\end{array}$ & $\begin{array}{l}-0.22 \\
(-0.81 \\
0.37)\end{array}$ & 0.46 \\
\hline \multirow[t]{2}{*}{$\begin{array}{l}\text { Anterior } \\
\text { Insula }\end{array}$} & L & $\begin{array}{l}-0.02 \\
(0.66)\end{array}$ & $\begin{array}{l}-0.24 \\
(0.93)\end{array}$ & $\begin{array}{l}-0.03 \\
(0.66)\end{array}$ & $\begin{array}{l}-0.08 \\
(1.21)\end{array}$ & $\begin{array}{l}-0.16 \\
(-0.71 \\
0.38)\end{array}$ & 0.55 \\
\hline & $\mathrm{R}$ & $\begin{array}{l}-0.16 \\
(0.75)\end{array}$ & $\begin{array}{l}0.00 \\
(1.03)\end{array}$ & $\begin{array}{l}-0.20 \\
(0.84)\end{array}$ & $\begin{array}{l}0.00 \\
(1.49)\end{array}$ & $\begin{array}{l}-0.00 \\
(-0.68 \\
0.68)\end{array}$ & $>0.99$ \\
\hline pACC & L & $\begin{array}{l}-0.22 \\
(0.88)\end{array}$ & $\begin{array}{l}-0.37 \\
(1.12)\end{array}$ & $\begin{array}{l}-0.30 \\
(0.98)\end{array}$ & $\begin{array}{l}0.01 \\
(1.35)\end{array}$ & $\begin{array}{l}-0.37 \\
(-1.00 \\
0.25)\end{array}$ & 0.24 \\
\hline
\end{tabular}




\begin{tabular}{|c|c|c|c|c|c|c|c|}
\hline $\begin{array}{l}\text { pACC to Ant. } \\
\text { Insula }\end{array}$ & $B-L$ & $\begin{array}{l}-0.22 \\
(0.83)\end{array}$ & $\begin{array}{l}0.10 \\
(1.53)\end{array}$ & $\begin{array}{l}-0.47 \\
(1.12)\end{array}$ & $\begin{array}{l}0.41 \\
(1.57)\end{array}$ & $\begin{array}{l}-0.31 \\
(-1.10 \\
0.49)\end{array}$ & 0.44 \\
\hline & $B-R$ & $\begin{array}{l}-0.16 \\
(0.90)\end{array}$ & $\begin{array}{l}0.05 \\
(1.50)\end{array}$ & $\begin{array}{l}-0.53 \\
(0.96)\end{array}$ & $\begin{array}{l}0.23 \\
(1.09)\end{array}$ & $\begin{array}{l}-0.18 \\
(-0.87 \\
0.51)\end{array}$ & 0.60 \\
\hline $\begin{array}{l}\text { pACC to } \\
\text { Amygdala }\end{array}$ & $B-L$ & $\begin{array}{l}-0.24 \\
(0.98)\end{array}$ & $\begin{array}{l}0.48 \\
(1.56)\end{array}$ & $\begin{array}{l}-0.29 \\
(0.89)\end{array}$ & $\begin{array}{l}0.25 \\
(1.38)\end{array}$ & $\begin{array}{l}0.24 \\
(-0.53 \\
1.00)\end{array}$ & 0.54 \\
\hline & $B-R$ & $\begin{array}{l}-0.05 \\
(0.83)\end{array}$ & $\begin{array}{l}0.26 \\
(1.27)\end{array}$ & $\begin{array}{l}-0.12 \\
(0.77)\end{array}$ & $\begin{array}{l}-0.03 \\
(1.16)\end{array}$ & $\begin{array}{l}0.30 \\
(-0.33, \\
0.92)\end{array}$ & 0.35 \\
\hline
\end{tabular}

Abbreviations: B: bilateral; Hemi.: hemisphere; L: left; R: right; pACC: pregenual anterior cingulate cortex; sgACC: subgenual ACC.

Figures 


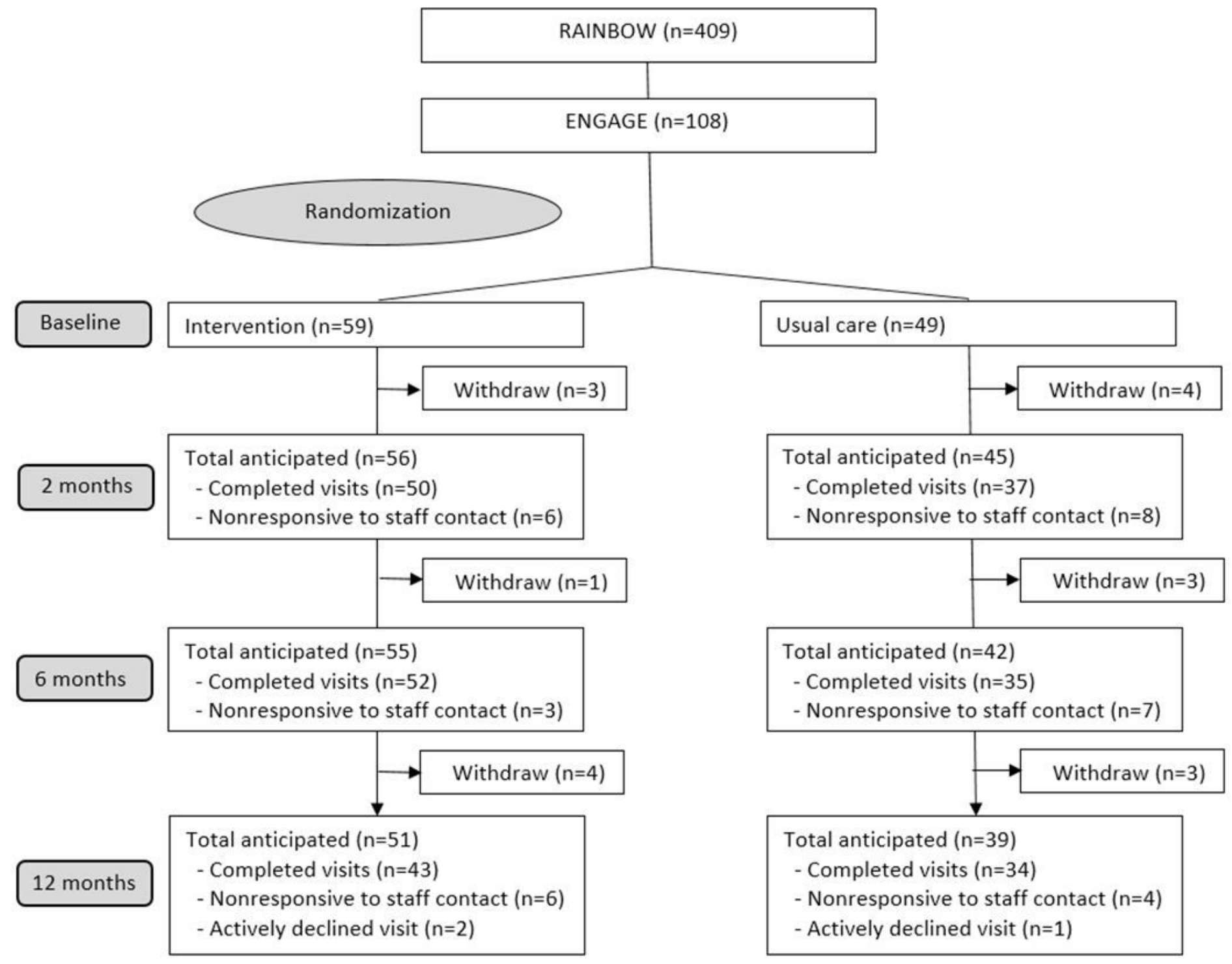

\section{Figure 1}

ENGAGE Consort Chart.

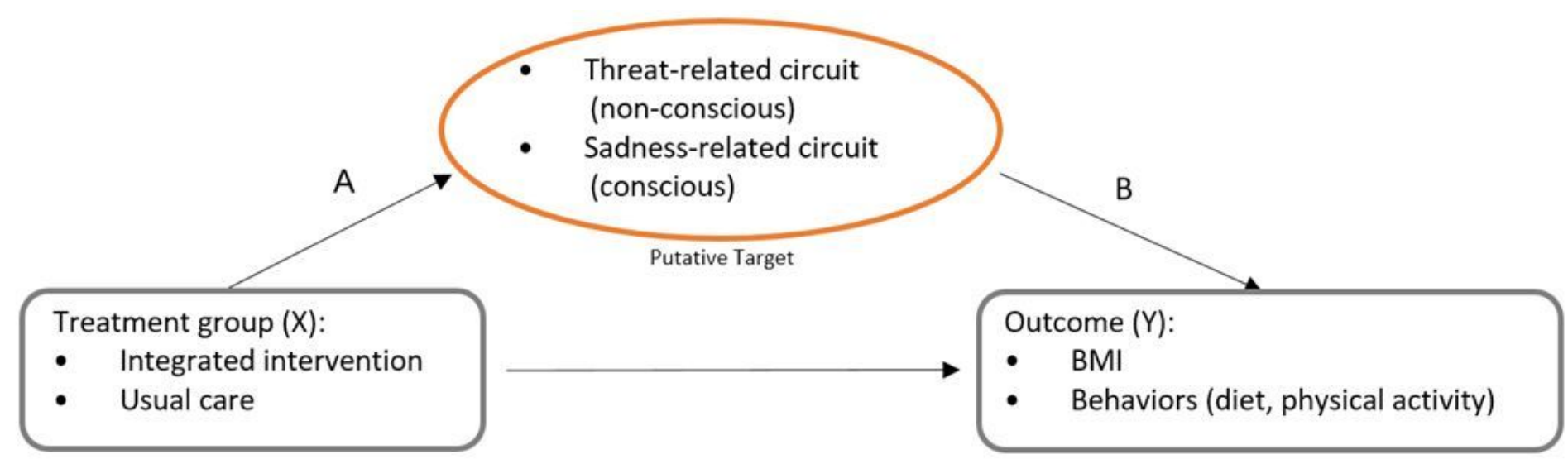

Figure 2 
Conceptual Framework for Mediation Analysis.

Problem solving therapy-induced negative affect circuit engagement at 2 months mediates subsequent physical activity improvements at 12 months
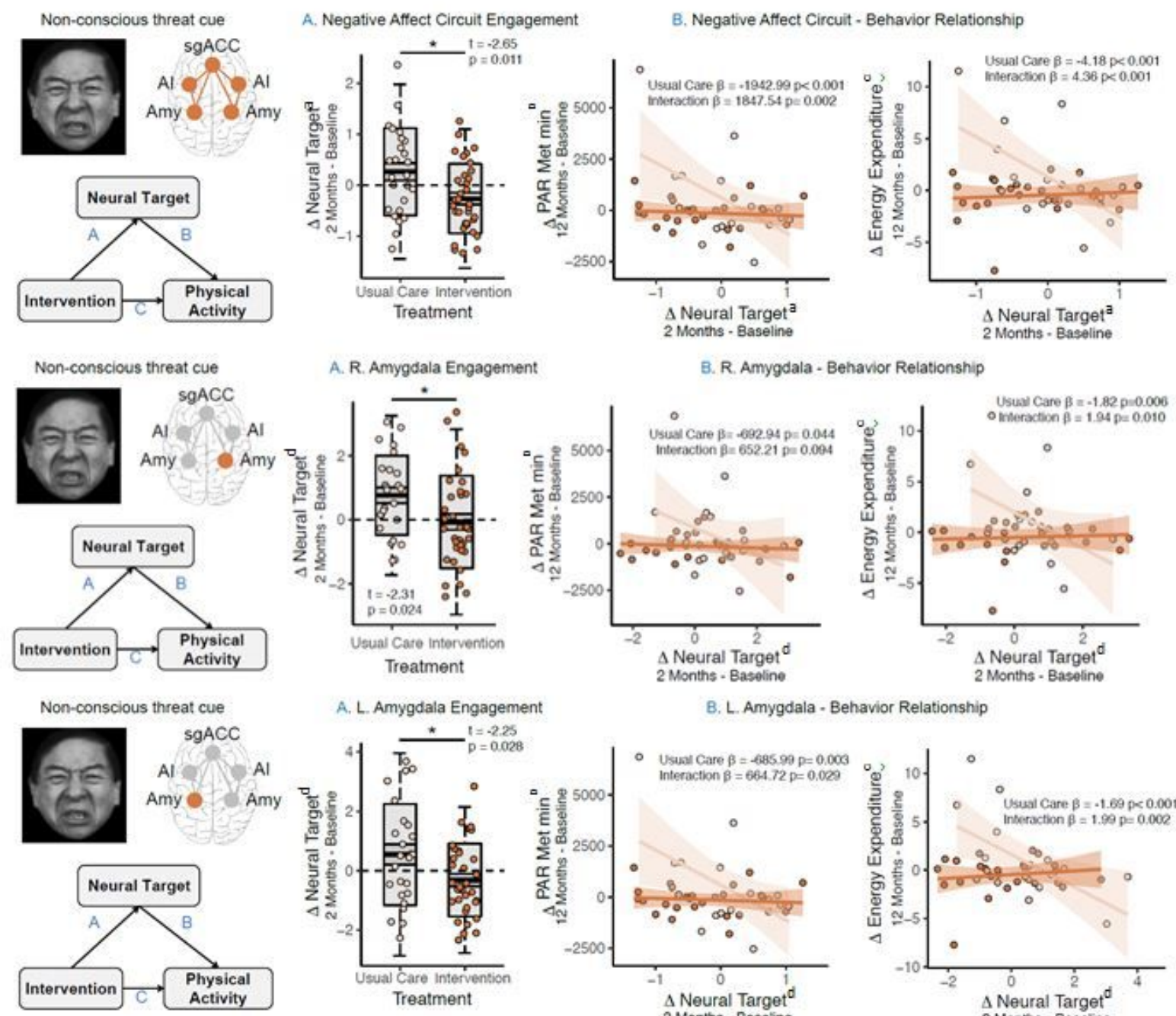

B. L. Amygdala - Behavior Relationship
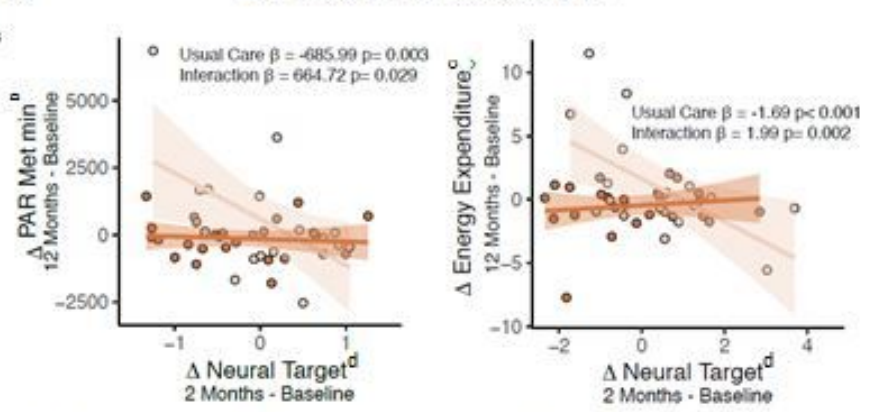

Problem solving therapy-induced amygdala-ACC connectivity engagement at 2 months mediates subsequent weight loss at 6 months and fruit and vegetable intake at 12 months
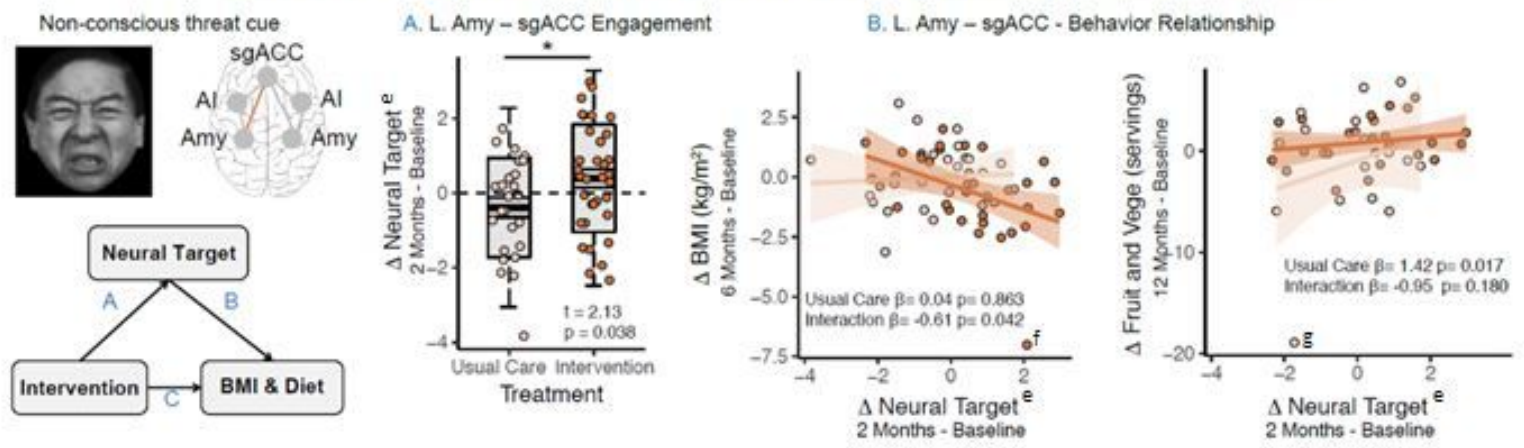

\section{Figure 3}

Mediation Results Abbreviations: ACC, anterior cingulate cortex; Amy, Amygdala; BMI, body mass index; BOLD, blood oxygenation level dependent; L, left; MET, Metabolic Equivalent Task; PAR, physical activity recall; sgACC, subgenual ACC * $P<0.05$ a Overall score from BOLD derived activation and connectivity within the negative affective circuit. b The interview-administered Stanford 7-day Physical Activity Recall 
provided MET minutes/week for leisure moderate activity. Leisure-time physical activity = non-workrelated moderate activity $\mathrm{min} / \mathrm{wk} \times 4 \mathrm{METs}+$ hard activity $\mathrm{min} / \mathrm{wk} \times 6 \mathrm{METs}+$ very hard activity $\mathrm{min} / \mathrm{wk} \times$ 10 METs. One MET is defined as the energy expenditure for sitting quietly. c The Stanford 7-day Physical Activity Recall data also provided estimates of total daily energy expenditures. Total energy expenditure $=$ sleep hours $\times 1 \mathrm{MET}+$ light activity hours $\times 1.5 \mathrm{METs}+$ moderate activity hours $\times 4$ METs + hard activity hours $\times 6$ METs + very hard activity hours $\times 10$ METs. $d$ BOLD activation vs. neutral cue, z-scored e Task dependent connectivity between the amygdala and sgACC as measured by psychophysiological interaction (PPI) for threat vs. neutral cue $\mathrm{f}$ Influential data point was verified. Sensitivity analysis using winsorized data $( \pm 3 \mathrm{SD})$ showed that significant interaction effect remained unchanged: Usual care effect $\beta(95 \% \mathrm{Cl})=0.04(-0.40,0.49) ; P=0.84$; Interaction effect $\beta(95 \% \mathrm{Cl})=-0.58(-1.15,-0.02) ; P=0.04 \mathrm{~g}$ Influential data point was verified. Sensitivity analysis using winsorized data ( $\pm 3 \mathrm{SD})$ showed that usual care effect was no longer significant: Usual care effect $\beta(95 \% \mathrm{Cl})=0.87(-0.22,1.96) ; P=0.11$; Interaction effect $\beta(95 \% \mathrm{Cl})=-0.46(-1.79,0.88) ; P=0.49$ Notes: $\cdot$ Path $C$ effects reported in Ma et al. (2019) and Rosas et al. (2020) - For the box plots, the central thick black bar represents the mean, grey shaded boxes represent standard error (dark grey) and standard deviation (lighter grey) of the mean, and the whiskers represent 2 standard deviations of the mean

\section{Supplementary Files}

This is a list of supplementary files associated with this preprint. Click to download.

- AdditionalFile7.RAINBOWmainresultspaper.pdf

- AdditionalFile6.ENGAGEprotocolpaper.pdf

- AdditionalFile5.RAINBOWprotocolpaper.pdf

- AdditionalFile4.TIDieRChecklistWord.docx

- AdditionalFile3.CONSORT2010Checklist.doc

- AdditionalFile1and2FINAL.docx 